\title{
Consuming a Remotely Global Modernity in Recent Times
}

In 1957, the Gold Coast was the first African colony to achieve independence. It chose to call itself "Ghana," after the first of West Africa's fabled ancient empires. While the geographic boundaries of ancient and modern Ghana do not overlap, by adopting the name Ghana the modern nation-state sought to codify its firstcomer status to independence, and to remind its inhabitants as well as onlookers of proud African achievements of the past (Gocking 2005). Sixty years later, strong nationalist sentiment remains in Ghana, but pride in the deep past has greatly diminished. One way in which the ambivalent and contested relationship between past and present is negotiated is through food preparation and consumption. Young people perform their modernity by consuming "modern" foods associated with urban dwellers instead of the "traditional" foods of their ancestors. The foods considered modern tend to be imported, processed foods that are part and parcel of the global food system. Over the course of the nineteenth and twentieth centuries, societies around the world have witnessed a dramatic rise in the consumption of industrial food products. Some societies have responded by placing greater value in local foods as a way to reassert cultural identity, but in others local food practices are associated with poverty and tradition and as a result are stripped of their cultural capital (chapter 6; Wilk 2006b).

In this chapter and the one to follow, I consider how-and if - we might bridge the gap between foods considered traditional and modern, local and global, and how we might connect the past and present more generally. In this chapter, I focus on the second half of the twentieth century and the early twenty-first century (c. 1940s-2009), a time when industrialized foods rapidly made inroads. Instead of providing a comprehensive overview of modern food practices, I focus on the tensions inherent in growing, making, and eating food in this "remotely global" (Piot 1999) context. I consider how and why people may actively maintain 
continuities in some food practices and quickly abandon others. This investigation reveals how food mediates and reinvents the relationship between so-called tradition and modernity. Through the constant need to navigate change and continuity, Banda's cooks have devised a food system that values flexibility and persistence at the same time.

\title{
TRADITION VERSUS MODERNITY? WHY \\ DICHOTOMIES DON'T WORK IN WEST AFRICA
}

\begin{abstract}
Africa's ... smallholder farmers toil in a time warp, living and working essentially as they did in the 1930s.
\end{abstract}

—ROGER THUROW, THE LAST HUNGER SEASON, XIX

Some years ago, I was part of a group of faculty, students, and corporate employees who visited southern Africa as part of a food security internship program. The purpose of the trip was to expose the interns to the development arm of the corporation. We visited village after village that the corporation had helped, and in each we heard lines rehearsed for donor's ears. These visits were facilitated by partner organizations like USAID, whose representatives we also had brief opportunities to meet. It was in one such meeting that I first became aware of how pervasive the scarcity slot is in the development world, with real-life consequences for the men and women that are the subjects of their interventions. One USAID office was headed by a white South African who had fled black rule and-somewhat ironically-was now in charge of "developing" other black Africans. So I should not have been surprised when he described "the Africans themselves" as the biggest challenge to development. As he put it, when faced with answers to their problems, like how to grow more or eat more nutritiously, sometimes they just didn't listen. When asked how he dealt with this problem, he threw up his hands and said, in effect, "Well, some people just don't want to be saved."

The USAID director was only expressing what passes for common knowledge about doing development in Africa, as captured by the quote that opens this section, from an award-winning monograph on African agricultural development by Roger Thurow. I am by no means alone in finding these kind of approaches to development wanting; anthropologists in particular have long been critical of development discourses in Africa (e.g., Ferguson 1990, 2006; Malkki 2015). These critiques question the taken-for-granted assumption that externally driven modernity and development are a good thing. They highlight how outsider expertise is privileged at the expense of African agencies and knowledges (see also Mitchell 2002). In my view, the long-term histories that are the focus of this book bolster these critiques by empirically interrogating the notion that African foodways are timeless and unchanging.

At the center of many of these stereotypes is the idea that Africans-and how they eat and grow their food-are nonmodern. Yet the African food history that I and others have presented conjures a much different narrative. As I have discussed 
in previous chapters, African foodways have long been intertwined in global happenings, from the Columbian Exchange detailed in chapter 2 to the Atlantic slave trade (chapter 3) and colonial rule (chapter 4). Few areas of the world lie outside of the global processes that have created modern economies and sensibilities, yet modernity has been assigned to some places and not to others. This is of course a politically and racially motivated project (e.g., Escobar 2012; Ferguson 2006; Pierre 2012). In a colloquial sense, modernity refers to specific developments in the West that were assumed to radiate to far-flung locations as part of the process of globalization. Anthropologists have argued that we need to provincialize that Eurocentric view (Chakrabarty 2000), and that how globalization has been defined, experienced, and created varies across local settings (Piot 1999). Modernity is often juxtaposed against tradition, though in practice the two are co-created (Hobsbawm and Ranger 1983). Modernity is commonly associated with a certain present progressiveness, with being modern, where tradition is associated with a backward past. The past is very often Othered as pre- or nonmodern, reminding those considered modern how far they have come (Cobb 2005).

Yet African modernities often have a different and more complex appearance than Western ones. Piot (1999) characterizes village modernity in his Togolese example as "remotely global." He shows how many apparently traditional features of village life, like the dependence on subsistence agriculture, are actually quite modern and the products of centuries of interaction with Europeans. Piot (1999, 2-5) laments how so-called African traditions are often villainized in news story imaginaries about the African continent, where they are equated with remoteness and inability to change. Challenges like food insecurity are blamed on African societies themselves rather than on the global modernities of which they are a part. These stereotypes plague many development initiatives on the continent, in which, as the USAID officer remarked above, the major hurdle is perceived to be Africans themselves. Yet as Piot $(1999,2)$ remarks, these kinds of ideas betray a remarkable ignorance of African history, one that borders on willful amnesia. They also turn a blind eye to the diverse array of strategies and improvisations that villagers must use on a day-to-day basis to sustain themselves and their families. Characterizing African societies as bounded, local phenomena means that the global, colonial, and postcolonial processes that underlay present-day insecurities go unacknowledged (Piot 1999, 17), which effectively focuses any solutions on the wrong unit of analysis.

In this chapter, I make a case for the remotely global nature of Banda foodways in recent decades, as a counter to the misconception of African foodways as traditional and unchanging that characterizes most development initiatives and even the low valuation accorded local foodways by many Banda youth (chapter 6). While there are many studies of food globalization, very few have focused on the African continent (but see Ham 2017; Holtzman 2009; Koenig 2006; Rock 2019). Like the Kabre, whom Piot (1999) describes, people in Banda have long adopted and experimented with nonlocal foods and goods, and documenting these 
processes has been at the center of the Banda Research Project (Stahl 1999b, 2001, 2002, 2007; see also bandathrutime.matrix.msu.edu and exhibits.library.uvic.ca /spotlight/iaff). These scholars resist the temptation to discuss African practices in terms of strict dichotomies like local/global and traditional/modern, as Holtzman (2009, 155-57) has cautioned against. To divide foods into such arbitrary categories means missing the ambivalences and ambiguities that largely define change and continuity in food practices. For example, Holtzman's ethnography of Samburu food describes the shift from a subsistence pastoralist diet to one increasingly focused on the consumption of purchased grains. This complex process involves a move away from more culturally salient and preferred foods like blood and milk and toward bowls of what is pejoratively described as "dry stick" maize porridge. Some Samburu see this as a sign of cultural decay while others see it as an example of progress, but ambivalence is often at the heart of these explanations. By refocusing his analysis on locally defined shifts in foodways, Holtzman is able to highlight the ambiguities at the core of remotely global foodways.

In the pages to follow, I explore some of the primary tensions in foodways over the last sixty or so years in Banda. This time frame is only an estimate. Holtzman (2009) shows the futility of imposing Western binaries onto local foodways and I discovered this many times over in my conversations with interlocutors in Banda. One of my first such lessons came when I asked an elderly female interlocutor how old she was. She laughed in my face, as did every other woman over the age of fifty. ${ }^{1}$ Still, as an archaeologist obsessed with time I tried to establish a chronology of the changes people had seen in their foodways, through correlating a woman's life stage with certain major events like independence. While such a history would be useful for some, writing about shifting tensions rather than about linear events is more true to the experiences I recorded as well as to the nature of memory about food practices. To the best I can estimate, some of the earliest substantiated recollections in these interviews go back to the early 1940s, but most pertain to the last several decades. Most of my interview data was collected in 2009 and the tensions described in this chapter reference that point as "today," while acknowledging the limits of the present tense for capturing the rapid changes in food and farming that have continued to characterize the Banda area.

In the following section, I first consider how African food practices of this period have been relegated to a culinary underclass through discussion of Jack Goody's (1982) important work. Focusing on Banda next, I begin with the categories that local people deemed to be more stable, like seasonality, and move progressively toward the food practices that have seen the most change, ending with a discussion of food security. As will become clear, this scheme is inadequate to capture the dynamics of continuity and change, since even the most stable parts of the food system are constantly being reevaluated. Through discussing the tensions between choosing something new and continuing with something old, I try to bring local agencies and the constraints on choice to the fore. As a counter to 
the USAID officer's lament, I argue that it is the ability to make a choice, even if not under the conditions they would choose, that characterizes remotely global foodways in Banda. No wonder the "Africans" to whom he referred refuse to concede that ability.

\section{COOKING, CUISINE, AND THE CREATION OF A CULINARY UNDERCLASS}

Jack Goody's (1982) Cooking, Cuisine, and Class has long been considered a pathbreaking work on the anthropology of food, particularly in Africa (Mintz and Du Bois 2002), and looms large in any discussion of African foodways. Following the theoretical conventions of his generation, Goody's central project was comparative, seeking to understand how and why his African case studies differed from what was known about food history in the rest of the world. He compared the foodways of the LoDagaa and Gonja of northern Ghana to those of Asian and European civilizations, and argued that African cuisines were largely undifferentiated in comparison. Specifically, Goody argued that Africa lacked haute cuisines, since he found no evidence of the specialized chefs, techniques, or ingredients that defined the elite cuisines in Asia and Europe. He explained the absence of African haute cuisines through a corresponding lack of strongly stratified social classes.

Goody's structural analyses are problematic on several fronts, though his highquality ethnographic data continue to provide insight. One of the most obvious critiques is his use of an essentially European and Asian yardstick to evaluate African foodways. While he did not intend to denigrate African cuisines, some scholars argue that his work is at least partly to blame for an avoidance of African food as a site of scholarly inquiry (Lyons 2007, 348). Goody's central project had the unintended effect of Othering African food practices in ways that continue to be commonplace among outsiders. African foods are not readily appreciated by most Western palates (Lyons 2007,348 ), for reasons I explore and this and the next chapter, leading scholars and foodies alike to ignore their culinary, cultural, and nutritional values. As I detail below, this plays out in all sorts of forms, from describing African foods with pejorative language to treating African foodways as one undifferentiated mass. Part of the problem is that African taste preferences are realized and expressed in different ways than Western ones. While Westerners value novelty, many West Africans value quantity, a point raised by Goody (1982, 67-68) and expanded by De Garine (1997).

One consistently overlooked quality is texture, of which people in Banda and elsewhere in West Africa are exceptionally discriminating consumers. The importance of texture is readily apparent to the ethnographer interested in food preparation, even with an unskilled Western palate, because creating the right texture takes tremendous skill and time on the part of the (usually female) cook. Given his fascination with haute cuisine, which is by and large discriminated on the basis 
of specialized preparation, I was surprised to discover that Goody (1982) devoted very little of his energies to elucidating African food preparation practices. In his chapter on LoDagaa and Gonja foodways, preparation receives less than three pages of coverage, while production and consumption receive over twenty pages each. This may simply reflect his positionality as a man, but it also may stem from his earlier interest in surplus production as the root of differences in Africa versus the rest of the world (Goody 1977; Goody 1982, 58-61).

One last critique needs to be made, and that is that Goody's structural and comparative framework does not wholly match the data he collected. His book is based on thirty years (1949-79) of repeat visits to Ghana during the transition from colonial to independent government. This makes his work an excellent comparison point for my investigation of changing foodways in Banda over a similar time frame. What is odd about his resulting work is that although change is frequently mentioned, he does not structure his analysis around those changes, instead focusing on the structural differences between African and Eurasian societies, which are less meaningful for understanding African foodways as a whole.

These critiques suggest that Goody's work was very much a product of its time and as a consequence many of his key positions need to be reevaluated. Fortunately, he presents a great deal of high-quality ethnographic data and observations, which I've used as points of comparison to Banda, particularly since they cover a similar stretch of time and correspond to societies that are geographically proximate to Banda. In the pages to follow, I tack back and forth between Banda's foodways and those of the LoDagaa and Gonja as described by Goody, but expand the focus to food preparation and women's work.

\section{THE SEASONALITY OF CUISINE}

When I first approached men and women in Banda to talk about changes they had seen in food practices over their lifetimes, the most common response I received was that there had been no change. At first, I was more interested in changes than in continuities, but as the global food literature has pointed out, continuity too is agential, and is often actively protected and promoted as a means to deal with external pressures (Wilk 2006a, 2006b). In this and subsequent sections, I begin by talking about elements of cuisine that are considered more stable before moving to some of the major changes in Banda's culinary landscape. As I will detail in coming pages, continuity is characterized by a remarkable degree of fluidity, one that actively incorporates considerable change while retaining the overall shape of food practices.

Foods have seasons, as my interlocutors often said, and in Banda there are two major seasons that dominate the agricultural and culinary landscape: the wet season, when the most rainfall is received, corresponds with the growing season, whereas the dry season is characterized by the coming of dry Harmattan winds 
from the Sahara. In practice, farmers in Banda recognize seven seasons that take into account varying amounts of rainfall and suggest when it is best to plant certain crops (figure 5; Logan 2012, 51-56). People used to rely on two major staples that are differentially available based on the season. Yam fufu (gbosro or simply sro [literally, food] in Nafaanra) is the primary food from the beginning of the yam harvest, sometime in August or September, until they run short. Tuo zafi (Hausa for "hot porridge"; kambs in Nafaanra), or TZ, as it is known in Ghanaian English, is a thick, firm preparation of a polenta-like consistency made from grain and cassava flour. It dominates when yams run out and is eaten throughout the wet season. Other staples from southern urban areas, like kenkey and banku, both variations of fermented maize dough, have also gained in popularity.

Soups (chiin in Nafaanra) add flavor and texture to fufu and TZ and also utilize seasonally available plant and animal foods. Yams are often complemented by soups made from ingredients available in the late wet and early dry season, which during the wetter parts includes wild greens, freshly harvested fnumu (squash seeds) or groundnuts (peanuts), as well as by tomato-based "light" soups made from fresh tomatoes, garden eggs (small eggplants), and okro (okra). ${ }^{2}$ As the weather dries and these ingredients become more scarce, people make soups out of dried (e.g., leaves and okro) or purchased (e.g., canned tomato) alternatives. Other purchased alternatives include palm nuts from the wetter south, which are made into a rich, velvety palm nut soup. When the wet season returns, people complement TZ with soup made from fresh okro and other vegetables, including a wide range of cultivated and wild leafy greens. Meat or fish in small quantities are a frequent ingredient in all soup varieties; the soup is considered "raw" and not very nutritious without their presence.

Within the confines of seasonal food availability, people enact a number of taste and texture preferences. Chief among them is the need to consume soup with a "slippery" texture as an accompaniment to tuo zafi, but not to fufu. A slippery soup acts as a vehicle that guides the tuo zafi down one's throat, meaning there is no need for chewing first, since, as people told me, the "mortar has done the chewing for you." As Richards ([1939] 1995, 39) recounted among the Bemba, this desire for slipperiness may relate to the (formerly) gritty nature of the starch, which in times past included extraneous matter from grinding stones. Okro is chief among the mucilaginous vegetables, but women also use a selected array of wild leaves that impart the same textural quality. Both okro and one wild leaf, lom, are dried so that this texture can be produced in the dry season. People also extend the seasonal availability of some other products by purchasing processed alternatives like canned tomatoes or sardines.

At the time this research took place, in 2009, most farmers focused on growing enough subsistence crops "to eat and to sell." This is a low-risk strategy, since it insures that food is available from one's farm in most cases, though as discussed in chapter 4 , it also has some disadvantages. Besides staple carbohydrate crops 
MONTH

SEASON (ENGLISH)

SEASON (NAFAANRA)

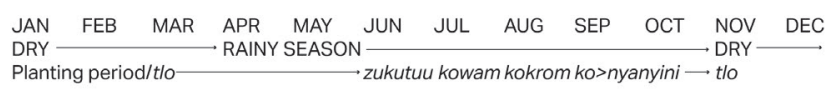

Yams (white \& water)

1]

IIIIIIIIIIIII

Cassava (whole field) 6 mo. varieties

2 yr. varieties

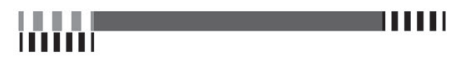

Cassava (partial field)

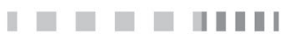

Pearl millet/Sorghum

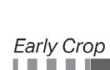

|| || || ||

Maize

Early Crop

Late Crop

IIIIII || || ||

IIIIIIIII

Okra

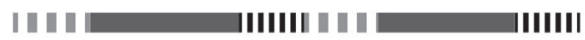

Squash seed

|| || || || || |II|

Beans

|| || || || || ||

Groundnuts

| || || || | | IIIII

\begin{tabular}{lllll}
\hline KEY Prepare land & Plant IIIII II & Grow (Weed) & Harvest IIIIIII
\end{tabular}

FIGURE 5. Agricultural cycle in the Banda area, 2009. Crops marked with an Africa symbol are indigenous to the continent.

like yams, cassava, sorghum, and maize, other crops in this eat-and-sell category include peanuts, fnumu, and beans (mostly cowpeas). Vegetables including okro, garden eggs, peppers, and more are also grown on a smaller scale. Many farmers also grow cash crops, particularly if they have access to additional land or to farming inputs like fertilizers and pesticides. Cash-cropping likely has a long history in Banda, extending into the colonial era and including crops like cotton, peanuts, tiger nuts, and tobacco. In 2009, farmers tended to focus on teak, which took many years to grow but had potentially significant returns, as well as cashew. Ann Stahl (personal communication, 12/2018) reports a significant shift to cashew in the last decade, even at the expense of yams, a highly prized food.

Although seasons do provide a natural rhythm to people's food routines, seasonal food availability is not separate from global forces but is shaped in a considerable way by climate change as well as by market integration. A shift in rainfall regimes is one area that people have little control over, one that is having major impacts on what people grow and eat. Farmers complained frequently to me of erratic rainfall, with some years receiving too much rain and some years too little, as well as of increasing unpredictability regarding the onset of the rainy season. Meteorological data from Kumasi confirms these complaints, showing a reduction in rainfall beginning with the Sahel drought of the late 1960s-early 1970s, which marked the beginning of a drought that continues to this day (figure 1; Shanahan et al. 2009). The timing of the start of the rains is particularly problematic and can upset the entire agricultural calendar (figure 5). A late onset, for example, means 
a shorter growing season and smaller or less productive crops overall. General unpredictability means farmers are unsure as to when to plant their crops in order to take full advantage of the rains. As one farmer put it, the amount and duration of the rainy season changes, but crops still need the same pattern of rainfall. If the rains do not cooperate, harvests and the people who depend on them suffer. Some farmers noted that in bad years there was barely enough to harvest, and certainly not enough to sell.

Changing rainfall is not the only pressure on Banda farmers; most farmers noted that another significant change was the need to produce a greater quantity of crops. My interlocutors described this as a significant shift since the days of their parents, when subsistence farming was the norm. Increased demand for cash meant that they were now pressed to produce enough to eat and to sell at market. The pressure to produce an increased quantity, particularly in the face of declining and abnormal rainfall regimes, has had several negative effects. Several farmers mentioned increased pressure on the land due to the need to farm more. Farmers could intensify production through the application of fertilizers, but this input was deemed too expensive for most. Instead, many people have adopted an extensification strategy, farming larger or more parcels of land in order to produce more. Although Banda's low population in the last century has meant that land has usually been abundant, that is starting to change as people try to keep up with changing demands for cash. One notable impact is that people are reducing the duration of fallows on land, with negative impacts on soil nutrients. While many farmers described a ten- to fifteen-year fallow as ideal for growing yams, most remarked that they often shortened this to five years, the minimum number needed to grow cassava and guinea corn.

As of 2009, with the exception of plots with cashew or teak trees, parcels of land are generally farmed for two years before being left to fallow. To prepare a field for planting yams, grasses are burned and non-useful trees are removed. Fruit trees and other useful trees are left in the fields. Other small trees or branches are often left in place or are added to help stake the growing yam vines. Mounds are raised after a little rain when it is easier to dig, though when this rain will fall is very unpredictable of late. Field preparation typically occurs in the very end of the previous wet season or the beginning of the dry season. In a first-rotation field, yams are the first crop planted in the mounds, sometimes as early as November, but generally sometime between January and April. Freshly planted yam tubers are often covered with spare vegetation and dirt to protect them from the dry-season sun until the rains start. As soon as yam planting is finished, other creeping crops like calabash or cowpeas can be planted in the mounds, taking care not to plant those that will quickly grow and overshadow the fledgling yam vines (figure 6). Okro can also be planted in the mound at this time, but is not usually planted in quantity as it is produced primarily for local consumption. Later, maize is often also planted in the sides of the mounds. Cassava may be planted along the edges of the fields 

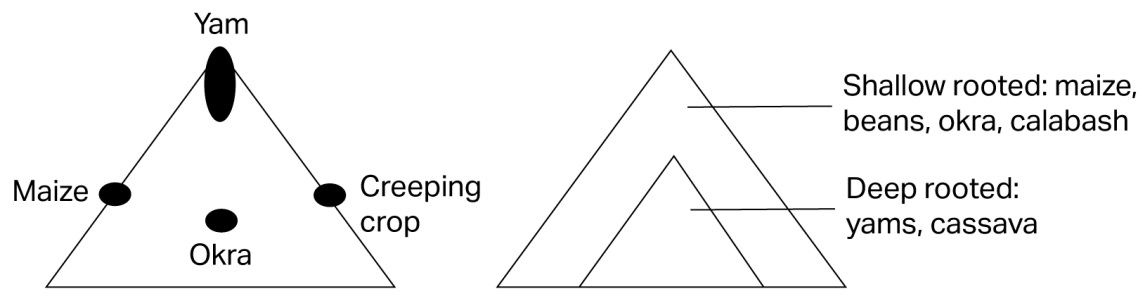

FIGURE 6. Schematic cross-section of mixed farming on mounds.

in rows; since it is deep rooted, cassava is not planted in the same mounds as yam so as to avoid competition for the same soil nutrients. After these crops are planted, the farmer weeds or waits for the crops to sprout and then weeds the field. Ideally, this portion of the agricultural cycle occurs in the late dry season and early wet season, so that by the time planting is finished there has been adequate rainfall for both; however with the changing timing of the rainy season's onset, planting may occur too early or too late to benefit from the rains.

In this first rotation, staple crops are grown on mounds that function as microenvironments providing a niche for each crop. This ingenious system takes advantage of the different depth and soil requirements of each crop (figure 6). Yam and cassava require deep, loose, well-drained soil, which the mound provides. This leaves the top layers of soil free for shallow-rooted crops like beans and okro. Timing is also critical; all of the crops grown in the top layer of the mounds mature in four months, compared to six months for yams and six to twenty-four months for cassava. This insures that the crops in the top layer do not interfere with yam growth, and the yam plant is not yet very large at the time they are harvested. Yams or cassava are then left in the field to mature; yams are generally ready in August or September. Cassava can be harvested at the same time in the case of six-month varieties; others remain in the field for another six to twelve months to reach optimal yield. In this case the crop may occupy the field for the duration of the second rotation. Because cassava remains in the field for so long, it can be harvested year-round if needed, although the tubers may not have reached maturity.

In the second year of cultivation, as soon as the yams are harvested, the land is cleared. After the rains begin, ridges are raised to plant fnumu or groundnuts. Sorghum (or millet in the past) is planted in June when the rains are most predictable. It is ready to harvest six months later. Maize can also be planted at this time, but this can be a costly option if it was planted in the previous rotation because of the need for chemical fertilizers. For this reason, sorghum is preferred in the second year. It requires only phosphorous, generally produces good yields, and can easily be sold. Weeding must be regular to ensure that spear grass, an introduced weed, does not compete with grain crops for nutrients. By year three, spear grass begins to dominate and most farmers do not find it worth their time and energy to cultivate another year in light of declining soil fertility. 
Monocrops of maize are also planted, though they are not as common as mound plantings. The reasoning is that because yams are highly valued for eating and for sale, it is a waste to use newly cleared fields just for maize. Maize can be ready in as little as three months, though it has not yet dried, making harvest more difficult. To ensure planting of two maize crops in one growing season, farmers can plant the first crop in April, anticipating a June yield; it can be left to dry for a few weeks to a month, which is preferable. Another maize crop is then planted in August, to be ready in November, before the other grain crops, at a time when yam stocks run low.

Both men and women do farm work, though in recent times there has been a shift to women having their own farms. This allows women a steady supply of income that is under their control, and also evens out risk of crop failure for the family. Traditionally, in both Banda and the areas studied by Goody $(1982,56)$, men did the heavy farming work such as clearing, weeding, planting, and removing plants from the ground at harvest time. Women assisted by weeding and tending, peeling and drying, and in final harvest practices such as gathering grain heads and processing them into clean grain. Yams were associated with men, who were responsible for growing them; women assisted by carrying seed yams to a new farm for planting and grown yams from fields to kitchens. These gender roles have changed as more and more women run their own farms and often produce lucrative yam crops. The most labor-consuming tasks are clearing of the fields, building mounds, and weeding. In recent times, both men and women have started to hire Dagaarti (LoDagaa) laborers from northern Ghana-the very same group Goody studied-to perform these tasks.

The hiring of farm labor is a relatively new development in central Ghana that is linked with the commodification of both food produce and labor. As Goody $(1982,73,88-91)$ details, men used to work first on the farms of the senior member of their household, then on their own. Laborers, both relatives and not, were paid in beer and sometimes food, with the expectation that the host would reciprocate with his own labor and that of his kin in the future. My Banda interlocutors mentioned a similar system in Banda. This system worked because the unit of production loosely matched the unit of everyday consumption. Those who farmed together also shared prepared food and the same granaries. Even by the time of Goody's writing, this system was beginning to fray, and indeed in Banda it is no longer the norm. The unit of production and consumption has become the conjugal family rather than extended household, though in practice food is often shared to some members of the latter. Goody (1982, 88-91) blames this shift on integration into market-based economies, in which labor and its produce have cash value. In these settings it becomes difficult to engage in reciprocal labor relationships.

In order to deal with increasing demands for cash and changing rains, people have increasingly altered what they eat. In general, the crops that fetch the highest price at market are consumed less and less within farmers' homes, and are instead 
sold to purchase less-expensive staples. Cassava in particular is being consumed more and more. It is one of the most commonly farmed staples in the Banda area, and is cheaply and readily available throughout the year. While the tuber is nutritionally lacking, the leaves are full of vitamins and nutrients and are often made into an accompanying soup. Yams, as the most valued staple of the area, were still eaten at the time of my research, especially during the yam season in 2009, but it was more profitable to sell one's harvest and eat cassava instead. A recent intensification of cashew farming instead of yams means that people are now eating even more cassava (Ann Stahl, personal communication, 2018).

Farming while remotely global means producing crops for market. As I will discuss below in the case of pearl millet, this means some crops are abandoned because they fetch lower prices at market, while others that fetch higher prices, like yams, are sold instead of consumed locally. The proceeds are often used to buy the cheapest foods available rather than the most nutritious or desirable; this is a strategy that actively balances food preference with the need to acquire cash. Agricultural development dollars tend to promote research and expansion of a narrow range of subsistence crops, particularly maize and rice, which also has down-the-line impacts on food availability. Food practices in places like Banda are thus whittled into a form and shape that make sense given market constraints.

\section{"TUO ZAFI IS ALWAYS THERE FOR YOU": A FLEXIBLE CONSERVATISM}

If there is one constant in the African continent, it is change. Practices which retain some semblance of themselves over time have to allow for a high degree of flexibility in order to persist. People may readily adopt new ingredients but continue to use the same food preparation techniques and meal structures (Dietler 2007, 224). Tuo zafi or kambJ is a starchy staple that displays remarkable flexibility and staying power. It can be made from maize, cassava, pearl millet, sorghum, and probably any other starch that can be converted into a flour. To make this salient for Western audiences, consider the European mainstay of bread, which can achieve the proper texture using only a very narrow range of gluten-rich grains, and is nearly always made with just one-wheat.

People allow for this flexibility in ingredients by adhering to a very rigid and lengthy set of preparation steps (figure 7) that can transform virtually any starchy crop into a culturally recognizable product. To make tuo zafi, women must first produce a flour out of whatever staples they have available. In the olden days, women would have employed a grinding stone or wooden mortar, but today the overwhelming majority of women pay to have their starches ground at a diesel mill (see below). Flour from the mill is sieved to remove any chaff or large chunks, to insure that a desirable fine texture is achieved. ${ }^{3}$ Women add a bit of flour, usually maize or in the old days pearl millet, to a pot of boiling water to make a thin porridge. Once thickened, handfuls of maize, millet, cassava, or sorghum flour are 


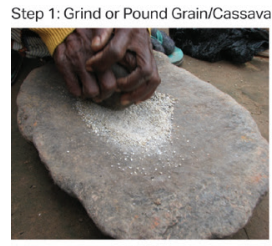

$\mathrm{OR}$

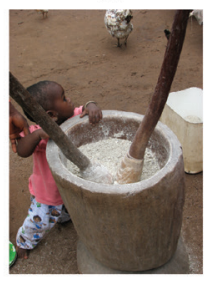

OR

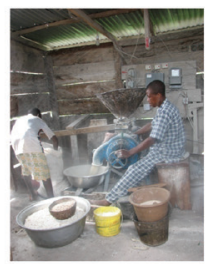

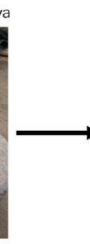
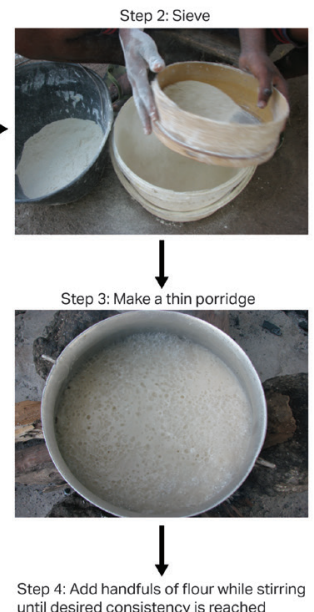
until desired consistency is reached

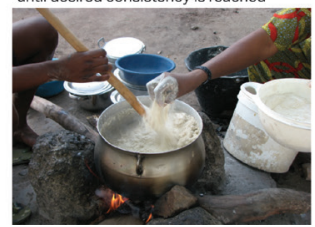

Step 6: Scoop out servings with calabash and eat
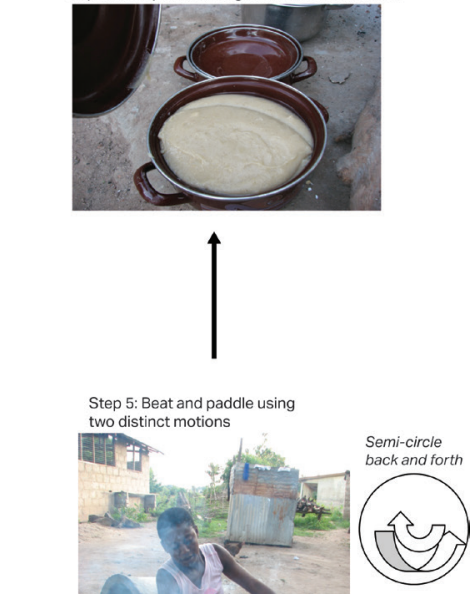

AND

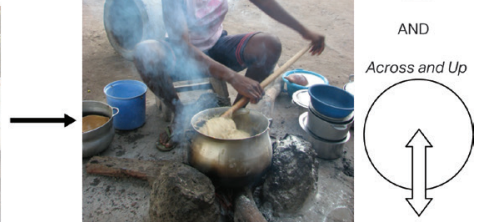

FIGURE 7. How to make tuo zafi.

added to the porridge, and rapidly stirred. As the mixture thickens, women adopt a special stroke, illustrated in figure 7 , which beats the tuo zafi into a very firm yet fine mass. The paddling is so vigorous the cook must secure the pot with her feet. In the past the process could easily result in broken earthenware pots, which is one of the reasons women were happy to switch to their aluminum counterparts.

Making tuo zafi is not easy. It requires considerable skill, strength, and patience. The whole process takes one to two hours with already ground grain from the mill; that time doubles if one has to grind or pound grain oneself. Women I talked to who were from outside of the region said it took several years to learn the requisite strokes and methods to make passable TZ; indeed my attempts to participate in making tuo zafi resulted in a sad, soft mess that little resembled the hard, springy masses people are used to and expect (results visible in figure 7). Making tuo zafi is a deeply embodied skill, one which young girls are often trained in starting in early adolescence, and are encouraged to make on their own only much later.

These narratives, which speak to the skill required to produce passable tuo zafi, also known in the wider region as tô, contrast markedly with common perceptions about the food by Westerners, who tend to regard it as a dull, monotonous substance. The most commonly used English translation of the food-simply "porridge" (e.g., Goody 1982) - does it no favors in this regard. Calling TZ porridge equates it with a tasteless gruel that takes little time or skill to prepare and does not account for the springy, firm texture that so many African consumers recognize 
and prefer. It is but one example of how African food is imbued with negative connotations, a tendency common to many formerly colonized areas (Janer 2007).

The benefits of being able to produce a culturally acceptable food from virtually any starch are manifold. It means new and nonlocal starches can readily be adopted, as we might imagine maize having been at its first introduction in the early seventeenth century. But it also means that if a preferred staple is unavailable, using an alternative one may not be perceived as quite as much of a hardship, because you are still eating a preferred local dish. That these capabilities are desired is clear in the persistence of tuo zafi throughout the twentieth century, though quickly produced foods like rice are increasingly available. While this continuity may relate to availability of funds to purchase imported foods, tuo zafi also has a staying power that speaks to how people have navigated the tensions between local and nonlocal foods as well as the varying availability of different staples.

\section{“OUT OF NEED": WILD LEAVES, HISTORY, AND \\ THE POWER OF PERSISTENCE}

The quintessential Nafana meal is tuo zafi accompanied by leaf soup (chiin). Leaf soup demonstrates many of the same qualities as TZ, but allows for a much greater degree of improvisation and creativity. The method of preparing leaf soup is fairly straightforward, since the primary goal is to soften the leaves of wild, collected, or cultivated species. This is accomplished through pounding, adding quake lime or ash from certain plants, and boiling, sometimes more than once. These methods can reduce almost any edible leaf into a soup. Flavorings and textures vary according to the staple served and the cook's preference.

But compared to TZ, which is usually made from the three commonly available starchy staples, leaf soup can be made from over sixty different wild leaves, as well as from the leaves of many common crops (predominantly cassava and cowpea). ${ }^{4}$ In some cases, the leaves are mixed with ingredients like garden eggs (piEwE), fnumu (squash seeds), and groundnuts (bongrE) to add texture, flavor, and nutrients. Additional flavoring agents may also be added, including meat or fish, wild mushrooms, fermented seeds (dawadawa, kapok, baobab, or cotton), or in more recent days, Maggi cubes (see below). A number of fresh wild leaves may be selected because they impart a desirable mucilaginous texture, often denigrated by outsiders as slimy. Finally, several types of leaves (especially the wild

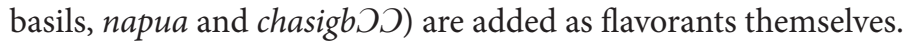

Leaves are obtained from wild, weedy, semi-cultivated, and domesticated species. At the time of my interviews, the majority were common weeds of cultivated or residential areas, many of which were also purposefully planted or encouraged in gardens and near villages. While the wide array of leaves used might be taken as an indication that women use everything in sight, this is not the case. Many 
taxa are toxic, and those that are used are clearly selected for certain qualities like texture or taste. The wide but selective range of taxa used demonstrates a detailed understanding of local environments as well as of plant lifecycles, which stands in contrast to the stereotype that Africans have little control over nature (see introduction). Collecting and nurturing the appropriate species requires substantial knowledge and time and represents complex people-plant relationships.

The use of wild leaves in soup is also a historical record of conflict and survival. Leaves figure quite prominently in oral histories of wars in the nineteenth century (chapter 3 ). This was a time of raiding and warring between the Banda peoples and neighboring groups, and the Banda were sometimes forced to flee from their villages at a moment's notice. Oral histories suggest that instability persisted periodically over decades, making farming on a regular basis impossible. People recount stories of their ancestors eating leaves from the bush: one person would try an unfamiliar leaf, and if they didn't die, the leaf was safe to eat. Hunted animals, along with cassava plucked from fields they were running through, are the only other foods associated with this time of upheaval. Oral histories, especially ones that recount such a dramatic time, are prone to exaggeration, but linguistic evidence suggests that leaves were a component of diet in times of need. The literal translation of the names of at least two wild leaves (kalameshia, kemeshiama), both associated with this period but no longer in use, is "out of need."

The use of wild leaves was repeatedly mentioned in interviews as a strategy to cope with seasonal and severe food shortage. The most severe shortage in living memory occurred in the early 1980s, in association with both a severe drought that affected much of West Africa and political upheaval in Ghana. Almost everybody interviewed said that during this time, people simply ate leaf soup and slept, since the starchy staples that usually accompanied the soup were in short supply. People also turned again to cassava, and the most unfortunate were forced to eat it without detoxifying it first, resulting in stomach complaints. Although many people today make use of leaf soup as both a regular and shortage food, few remembered the association with the nineteenth-century wars. This pattern of selective forgetting may index the ways that people remember past events via bodily knowledge. Recent work on food and memory has stressed the importance of bodily actions, repetition, and the senses in how people remember food and the events associated with it (Counihan 2004; Holtzman 2006; Sutton 2001). The bodily practices that people perform routinely-like cooking wild leaf soup or tuo $z a f$ - may be resistant to change in part because many become subconscious once the skills are initially acquired. These practices are learned from one generation and passed to the next, much like other crafts (e.g., pottery production), forming bodily archives of food history (see also communities of practice, e.g., Roddick and Stahl 2016; Wenger 1998).

Conservatism in food preparation practices may play an important role in navigating change and insuring food security. The preparation of both $\mathrm{TZ}$ and leaf 
soup displays remarkable flexibility and persistence. This conservatism-but at the same time, flexibility - in food preparation methods ensures food security because of the great range of plants and animals that can be used to produce the same culturally acceptable meals. Recall that modern definitions of food security entail that all people have enough food, can access it, and feel secure about their food supply (Maxwell 2001) - and that part of access and security is the cultural acceptability of any given food and the knowledge about how to prepare it. Food preparation methods in Ghana and West Africa more broadly are quite complicated and time consuming. Such complicated operational sequences serve the dual purpose of producing a culturally desirable product and of ensuring that any number of a wide variety of ingredients can be used. Flexibility is particularly important when dealing with unpredictable environments and economies, and frequent seasonal shortages that characterize much of the broader West African region today.

Persistence may also play a role in dealing with rare but severe food shortages, such as the 1982-83 drought. Minc (1986) has suggested that, in the Arctic, myth and ritual act to reinforce and remind people of coping mechanisms in times of both common and rare, severe shortages. Because leaf soup is the soup most closely identified with Nafana culture, we can conjecture that its social importance may help it to serve a similar function. Perhaps we can think of conservative food practices and preferences themselves as a way of preventing and dealing with food scarcity. As Wilk (2006a) has pointed out, keeping things the same takes work; conservatism in food practice might be best described as an actively maintained cultural value rather than a stubborn holdover from the preindustrial past.

Yet even the most conservative food practices are open to negotiation when they collide with opposing priorities, especially in remotely global societies like Banda. Some women observed that people were increasingly using the leaves of crops (especially bean leaves [susuwere] and cassava leaves [dwawere]) rather that collecting the wild and semi-wild herbs that account for much of the variation in daily diet. This is in part an environmental issue, as rising use of herbicides has decimated these plant populations and increased the amount of time women must spend searching for them. Collecting wild leaves is a laborious task in a context where women are under increasing pressure to generate cash income, which forms the subject of the next section.

\section{MAGGI: CONGEALED CUBES OF WOMEN'S LABOR}

To truly appreciate the work that has gone into passing down knowledge about wild leaves, as well as the time it takes to collect them, we have to consider the many pressures on women's labor. ${ }^{5}$ In this section I focus on how women have selectively adopted some food preparation technologies and ingredients that free up their time for other pursuits. In particular, I will focus on the uptake of imported and industrialized foods as well as use of the diesel-powered grinding 
mill, because they reveal the ambiguities and tradeoffs involved in adopting new foods and preparation methods.

The spread of industrialized foods over the last century has had lasting and significant impacts on both nutrition and women's labor all over the world. This food globalization has been associated with declining health (Popkin, Adair, and $\mathrm{Ng}$ 2013) and the erosion of local food traditions. Although viewed somewhat pejoratively by Western food movements today, it is important to acknowledge that these new processed foods also afford a host of opportunities. Industrial foods involve the processing and storage of ingredients into a more shelf-stable form, effectively lengthening the seasonal availability of some foods. Many African consumers consider these foods the most hygienic and pure, since they are produced in modern factories and are less susceptible to adulteration than home-prepared foods. But perhaps the chief attraction of these foods is convenience: cooks can simply pop open a can of tomatoes or sardines instead of preparing them from scratch (Goody 1982, 180).

In contrast to the West, where industrialized foods are today viewed with suspicion and disdain, in places like Banda industrial and imported foods in general tend to possess a higher cultural value than many local alternatives because in addition to alleviating the concerns mentioned above, they are associated with modern, urban living. This is not a new pattern; as discussed in the last chapter, the association of imported foods with status was commonplace among educated Africans in the colonial period (Goody 1982; Robins 2018). Today, there is also a general belief in Ghana that rural, village life is less desirable because it is less developed and therefore backwards. Most men and women who now reside in the Banda region have spent some time in an urban area, seeking out wage-labor opportunities or furthering their educations. These experiences expose young people to urban food habits, to which they aspire once returning to the village (chapter 6).

Several processed and imported food products have been adopted in Banda over the last three decades, though their use varies with economic class. Bread baked from imported wheat is not made in Banda, but can be found in Wenchi (the nearest large market town), along with canned milk, tinned coffee, and tea. These foods are uncommon among all but the most well-off individuals in Banda but are considered highly desirable. Whenever I was heading into the city, people requested loaves of bread from specific towns, since they appreciated the different recipes as well as the novelty of a food unavailable in Banda itself. While these requests could be interpreted as a sign that Banda residents valued novelty, my other experiments in that regard suggest this is not the case. Instead, there is a marked appreciation of foods from specific regions, including bread and various wild plants and animals, suggesting a developed sense of terroir or taste of place (Trubek 2009).

Asian rice is also considered expensive relative to other starchy staples, but is strongly preferred among younger women and is growing in usage. Rice is the 
mainstay grain of urban dwellers, which partially accounts for its higher status; it is also very quick to prepare compared to local starch dishes like fufu and tuo zafi. Fresh or frozen meat is highly sought after and is considered the ingredient that makes a soup "strong," or healthy, but it is consumed in very small amounts. Fish, usually in dried or canned form (e.g., Teacher brand mackerel), is cheaper and consumed more often. More commonly purchased are cheap soup ingredients, which also save women a considerable amount of labor. Canned tomato paste can be combined with vegetables to produce a quick light soup, which has become very popular in Ghana, enough to support the growth of Ghanaian tomato-canning factories.

The use of Maggi cubes-a Nestlé bouillon product most often found in shrimp flavor-captures the tensions at the heart of Banda's industrializing foodscape. Maggi is the ultimate industrial food success story in the African continent, in part because of its availability to all but the very poorest people. In northern Ghana, Ham (2017) describes ambivalences about Maggi's use as compared to locally available dawadawa. Dawadawa is a paste made from the fermented and ground beans of a wild leguminous tree (Parkia biglobosa) that is used as a flavor enhancer and nutritional booster in soups in Banda as well. But dawadawa's pungency gives it a strong smell that is much eschewed by urbanites, so much so that the women Ham interviewed described it as nonmodern. Maggi, on the other hand, provides a neutral smell and flavor that are deemed more widely acceptable. Yet a large majority of women still used dawadawa in their soups, because they recognize its nutritional qualities. Parkia biglobosa beans contain protein, which is enhanced through the fermentation process, while Maggi is almost pure sodium (although Nestlé has recently announced the addition of iron supplements for African markets). The fact that Maggi has not replaced dawadawa in Ham's study area is all the more surprising when one considers the tremendous amount of labor required to produce dawadawa paste from the raw beans, as compared to the simple unwrapping of a bouillon cube.

In Banda, the use of dawadawa persists to a limited extent alongside Maggi. Dawadawa was most commonly referenced when talking about wehan (figure 8), a steamed dish made during times of food shortage from ground Parkia biglobosa beans and cassava scraps. Many other flavoring agents have been abandoned. Seeds from baobab, kapok (kondo), and cotton (kombotoo) can be processed much in the same way as dawadawa, through grinding and fermentation, to produce flavorful additions to soups that help to substitute for meat. Wild mushrooms were also in widespread use in the past, but are no longer commonly used. The near abandonment of these alternatives is no surprise given the labor required to produce them. Maggi cubes in many ways represent women's labor, sacrificing distinctive flavor and enhanced nutrition for time spent in the kitchen.

Maggi's popularity may also correspond with a marked decrease in meat availability in Banda. People used to access a wide array of bush meat on a regular basis, but in recent years the supply of bush meat has declined rapidly. My interlocutors suggest that two forces are at play. The first is the enclosure of Bui National 


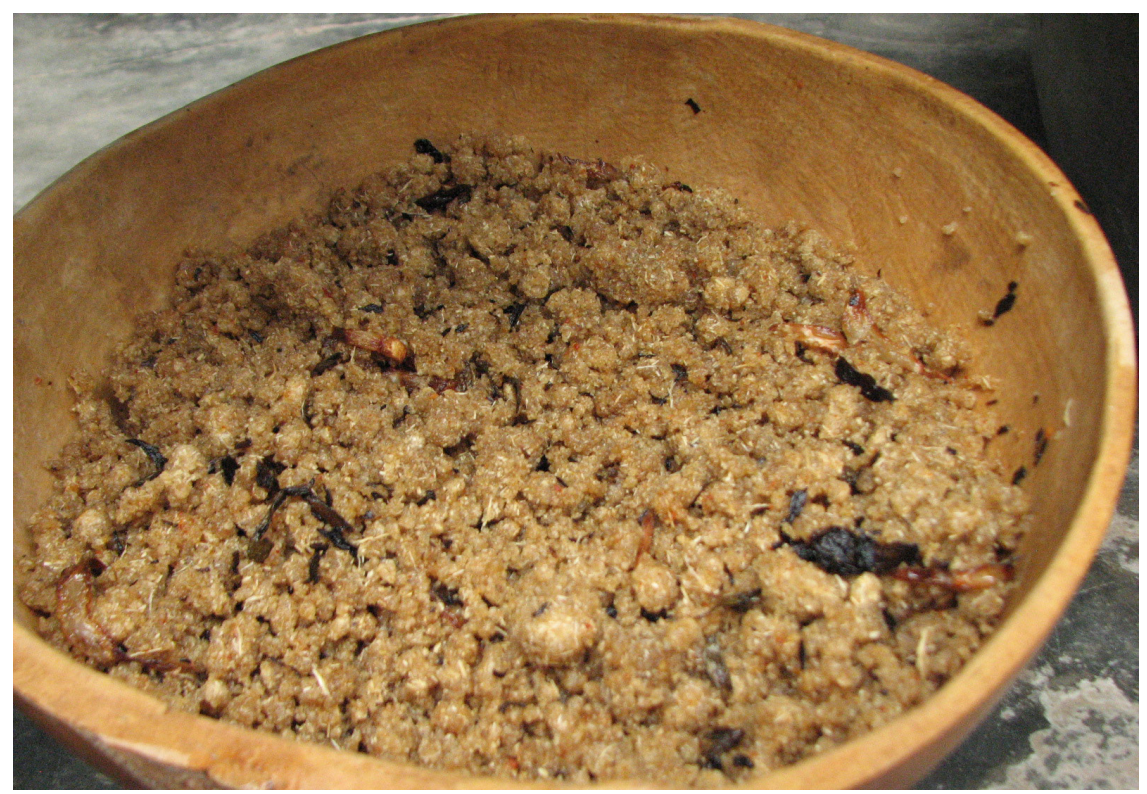

FIGURE 8. Wehan: steamed dawadawa and cassava, often eaten with a sauce (see table 2).

Park, which runs the length of the Banda Hills and expands westwards. Hunting is not allowed in the park, where "poaching" is deemed a punishable offense. Many people remarked that animals sought refuge in the park, causing access to bush meat to decline. Others related the lower availability of bush meat to overhunting in order to profit from the sale of the meat. Given Banda's long histories of wild animal consumption (Logan and Stahl 2017; Stahl 1999b), this is a significant departure from past culinary practice, and likely one with significant nutritional consequences. Maggi fills this gap in terms of flavor, but not in terms of nutrition. Increased use of dried and canned fish has also helped make up for the shortfall.

Whether it motivated the adoption of Maggi or was an unforeseen effect of it, how woman use their time has changed dramatically with new food technologies (Logan and Cruz 2014). But as Ruth Cowan's (1983) landmark study on the introduction of kitchen technologies in the United States cautions, new technologies (e.g., microwaves) do not actually ease women's share of labor within family units. Instead, women tend to fill those spaces with other productive, though often not remunerated, tasks (DeVault 1991). In Banda, there is a greater emphasis on remunerative activities than DeVault observed in her Chicago-based study. One of the most significant changes has been initiated by the introduction of the dieselpowered grinding mill, which has replaced the use of grinding stones and the need to pound grains or tubers into flour. Grinding or pounding enough grain for a single day's supply of flour used to take about two hours. Today, most women make use of the mill unless they are out of money to use it. But when mills first started arriving in Banda in the 1980s, women met them with mixed reactions. Some were 
hesitant due to the cost; others claimed that mills produced an inferior product that spoiled more quickly. But most seem to have welcomed the mill because of the time it freed up. Ama Benimbedei (approximately seventy-four years old), from Nyiire, told me that before the mill, women had to wake up very early, at around 4 a.m., to pound grain before heading to farm at 6 a.m. The mill freed up time, so that women could start to make soup earlier or go to farm earlier, or could sleep a bit more. Others, like Abena Sarabi (approximately sixty-five years old) recall devoting the extra time to activities that could generate cash, like soap-making or collecting kapok fibers for sale. Some women, including Ama Benimbedei, also brought up the unintended social impact of the mill. Many young women would gather in the early mornings to pound grain together. Elderly women talk about this as a fun gathering with songs, jokes, and gossip. They regretted the loss of this gathering time, and pointed out that women no long gather in groups on a regular basis, especially with the erosion of nubility rites (chapter 6).

The increasing use of industrialized foods as well as of grinding mills have also more fully incorporated women in particular into cash-based economiesapparently by choice. Buying these goods and services means that women save labor, but in order to access cash, women must invest that labor in productive activities, which begs Cowan's question of whether or not technologies actually save women time or worry at the end of the day. The need to access one's own cash stream in order to buy food has also resulted, for some women, in increased independence from their husbands. While women have long helped out in their husbands' fields, and even cultivated their own cash crops like tiger nuts, younger women are increasingly taking control of their own farms and growing the same crops as men. For some women this enables them access and control over their own finances. For others, who share finances with their husband, having their own farms is a risk-averse strategy. This is a major break with more gender-segregated agricultural tasks of the past, but men and women claim that it helps insure a harvest in the bad years. The skill of the farmers differs, and the added variable of cultivating different plots of land introduces a degree of randomness that helps deal with the often unpredictable microenvironments of the Banda area.

\section{PEARL MILLET, FOOD OF THE ANCESTORS}

Negotiating labor dynamics in an increasingly monetized remotely global economy has meant the reevaluation of what is grown, even in the case of a culturally valued staple grain like pearl millet. As I have shown through this book, pearl millet formed the mainstay of Banda diets for much of the last millennium. Pearl millet had tremendous cultural value and also afforded people a degree of resilience to major environmental changes, particularly drought. Although not the highestyielding choice, pearl millet was probably the best risk-reducing crop that Banda farmers could have grown. 
But the visitor to modern Banda would be hard pressed to find a single grain of pearl millet. Until I started talking with people and looking at archaeobotanical samples, I had no idea that pearl millet was until recently the mainstay of people's diets, or that it remained the most ritually potent food alongside yams. Yams are the well-known centerpiece of the Yam Festival, which is celebrated throughout forest-savanna and forested parts of Ghana, most notably in Asante (chapter 3; Bowdich [1819] 1873), and is frequently commented on by outsiders. The Yam Festival marks the harvest of yams in August or September. It is a centralized affair, with people contributing their share of yams to a larger feast. In theory, no one is permitted to eat or harvest yams until the festival takes place. The chiefs use some of these yams to make offerings to ancestral stools out of the sight of most Banda villagers.

But if yams are the food celebrated and controlled by authorities, it is pearl millet that forms the focus of household-scale ritual. It is fed to household shrines and more powerful regional shrines like the ancestral baobab Wurache near Kuulo Kataa. It is the meal prepared by doting mothers to mark their daughter's transition to womanhood and marriage. Pearl millet performs essential ritual and social functions throughout the year, perhaps because in times past it was the food that fed people throughout the year.

If pearl millet is so important, why was it abandoned? In my interviews, some people blamed the prohibitions around its use and harvesting, most of which were unique to pearl millet. It is said that if people fought while planting or harvesting or processing millet, one of them would die. Some elderly people said the youth today were too quick to anger, so much so that cultivating millet would have been injurious to their health. Pearl millet processing - the process of separating the grain from the husk-was subject to a special rule, that anyone who took part in the processing should receive a share. Many people argued that this is unfair, and that under this rule, even the fetus in a mother's womb would receive its own share. A functionalist interpretation of these taboos suggest they would have acted to maintain the peace and redistribute food to those who helped in processing. These were social strategies that may have played an important leveling role in the past, especially in times of food shortage. Of course, there may also be a more mundane explanation: processing millet is very uncomfortable, as the chaff bits make one incredibly itchy, and people must coat themselves in ash to avoid this. Given the discomfort involved, people may have simply needed a special incentive to participate. Whatever the ultimate purpose of these stringent rules, in a modern setting they may have decreased the farmer's harvest enough to make millet production unprofitable. The smaller amounts available to sell would have been exacerbated by the low price fetched by pearl millet at market. Most farmers are quite savvy about cultivating crops they can both eat and sell, and pearl millet may simply not have produced enough of a profit margin. With harvests also reduced due to changing rainfall regimes, pearl millet was simply too expensive to grow. 


\begin{abstract}
Local Name Preparation and Ingredients
(Nafaanra)

Pearl millet-based dishes

Fuura Add some water to whole pearl millet and allow to ferment for several days. A leaf called nyaadidinge may be added on the last day to allow it to ferment too. Grind millet and spices, sieve, and mix with water again to form balls. Boil. May pound hot balls again and add spices. Form new balls and roll in ground millet to serve. Smash and enjoy with pepper or milk. See figure 10 .

Koko (all millet) Thin porridge

Kotro papa Grind pearl millet (usually on a grinding stone), add a sprinkle of water and mold into balls. Boil balls. Once cooked, serve by breaking open balls and adding stew of shea oil, onion leaves ( $g a b u$ ), and pepper. Often eaten in the morning. See figure 9.

Sisa/sesa Grind pearl millet (or maize, but requires pre-frying, grinding, and subsequent sieving) on a stone. Add water during or after grinding. Pepper, salt, or sugar may be sprinkled on for additional flavor.

Tuo zafi (all millet) See figure 7.

Cassava-based dishes

Klakro

Grind fresh cassava and squish water out (effectively detoxifying bitter varieties). Add pepper and salt to mixture and form into small pieces. Fry in oil like a donut.

Wehan

Grind dawadawa beans into flour and mix with cassava flour (or "chaff," scraps from sieve unusable for TZ). Mix with water, and put in pot to steam into cake. Add sauce of shea oil, pepper, garden eggs, and salt. See figure 8.
\end{abstract}

Maize-based dishes

Chobi or brempo

Cut fresh maize off the cob. Add groundnuts and flewe, a wild leaf. Cook and serve with oil and pepper

Dibudibu

Pound maize, sieve, and form into balls. Boil balls, and add sauce of onion leaves ( $g a b u)$, pepper, oil, salt to serve.

Kwasidaman Pound maize and sieve. Use the residue from the sieve, add water to it, and cook. Made before the grinding mill came; now impossible because you do not get the "chaff" from sieving.

Nam During drought, people with money would buy maize and grind. They would add maize flour to water and cook until hard. Pepper, salt, and onion were added to serve.

Wenjor Grind maize and prepare a special tuo zafi. Cut and cool and save. When

(all-maize TZ)

YวगrJdDkono or chapila ready to eat mash like kenkey with water and add honey.

Fresh maize is cut off the ear and pounded with salt and pepper. The mixture is folded into maize husks, which are tied shut and cooked in boiling water. See figure 11. 
TABLE 2 (Continued)

\begin{tabular}{ll}
\hline $\begin{array}{l}\text { Local Name } \\
\text { (Nafaanra) }\end{array}$ & Preparation and Ingredients \\
\hline $\begin{array}{l}\text { Other dishes } \\
\text { Dankatere }\end{array}$ & $\begin{array}{l}\text { Multiple fruits can be prepared this way. Pick ripe fruits and pound if } \\
\text { needed to release flesh from seeds. Put into basket and add water, and let } \\
\text { sit overnight. Run through a sieve to remove chunks. Cook over fire with } \\
\text { quicklime and cool. Serve as beverage, especially to children. }\end{array}$ \\
& $\begin{array}{l}\text { Prepare in the same way as kotro papa, but use bean flour and mold into a } \\
\text { special leaf for boiling. See figure 12. }\end{array}$ \\
Gora & $\begin{array}{l}\text { Pound and cook bean leaves (susuwere) as for leaf soup. Pound fnumu } \\
\text { (seeds of Lagenaria siceraria, bottle gourd) and cook separately. Pound } \\
\text { cooked leaves again and add cooked fnumu to mixture. Add oil, pepper, salt, } \\
\text { and onion to serve. }\end{array}$ \\
Seed cakes for soup & $\begin{array}{l}\text { Use kondo (cotton), sisre (dawadawa), or kombotoo (kapok] seeds and grind. } \\
\text { Allow to ferment and form into cakes. Add to soups for extra flavor and } \\
\text { nutrients (also see Ham 2017). }\end{array}$ \\
& $\begin{array}{l}\text { Dry the heads of yam, which are usually very hard and thus rejected for fufu } \\
\text { preparation. Grind into a flour and mix with water, and cook in the same } \\
\text { way as wehan. Add shea oil, salt, and pepper to serve. }\end{array}$ \\
\hline
\end{tabular}

As an ingredient, pearl millet is not only much more nutritious that maize or rice, but it can be prepared into a wide array of foods. I offer a detailed list of these dishes, as well as a host of others made from various ingredients, and how they are prepared, in table 2. For the most part, these dishes are no longer made in the area today, and knowledge of how to make them is also disappearing. In 2009, most women in their twenties had never seen them made; women in their thirties and forties had seen their mothers make them but did not cook them themselves. Yet when these dishes were cooked for the Olden Times Food Fair described in chapter 6, people enjoyed their tastes and textures, which are quite distinct from common fare.

Describing three of these dishes, from the easiest to the most ornate to prepare, helps bring the versatility of millet to life, but also shows a very different range of culinary preparations than the everyday fare of $\mathrm{TZ}$ and $f u f u$ described above. The first is sesa or sisa, which is simply millet ground with water, though sugar can be added as well, often on a grinding stone. The Nafaanra word is also used to describe clay prepared in the same way for pottery making (see Logan and Cruz 2014 for an exploration of how these preparation techniques cross over between craft and culinary practice). This simple dish is one of the quickest to prepare, and was often provided to men going off to hunt or farm or immediately on their return. In one woman's words, it was the "olden-times fast kenkey," referring to the food often purchased on the go as a quick snack or meal. The food appears 


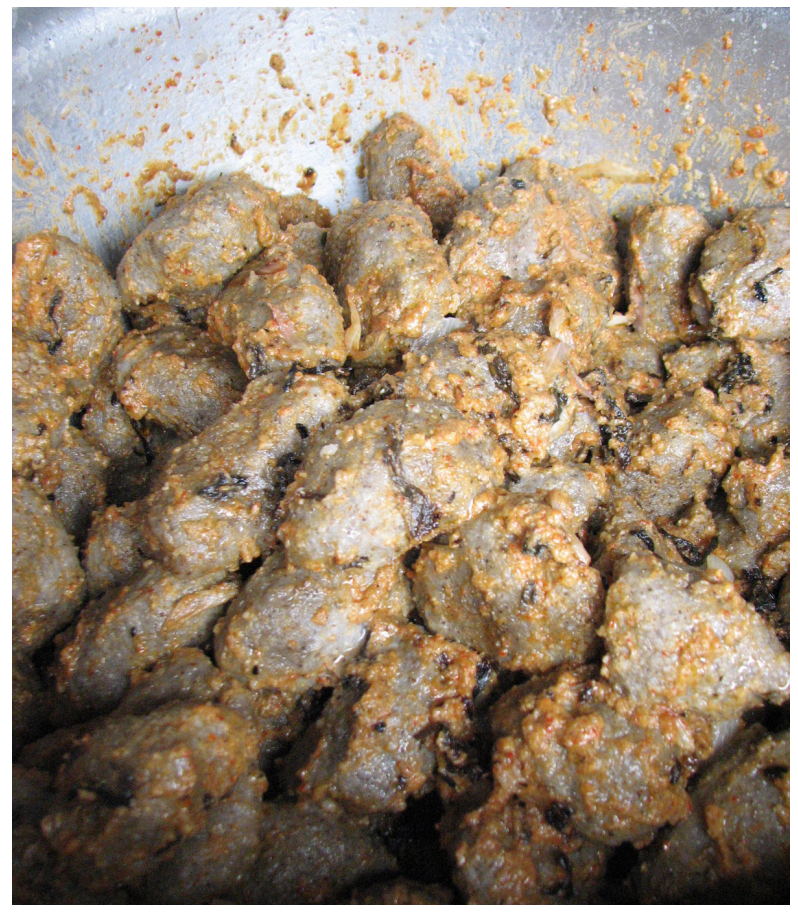

FIGURE 9. Kotro papa: boiled pearl millet balls tossed in shea oil, onion leaves, and pepper (see table 2).

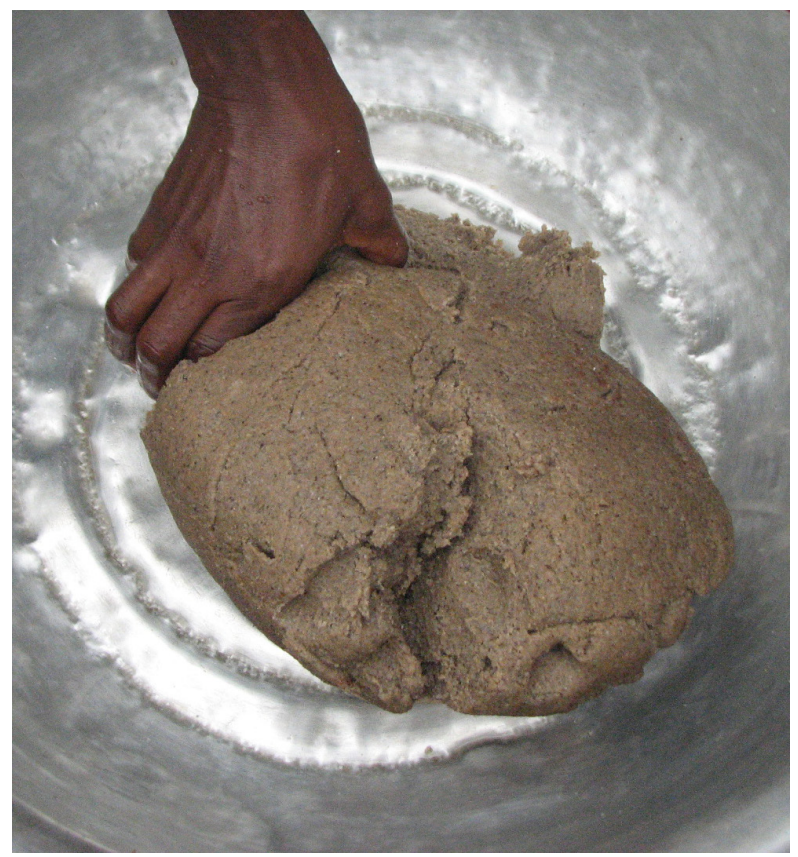

FIGURE 10. Fuura: heavily spiced, fermented pearl millet dough ready to be fashioned into balls and rolled in flour (see table 2). 
to have a long history; the same preparation was described as fare of Asante soldiers in the early nineteenth century (chapter 3 ). Consuming ground flour on its own was strategic as well as nutritious; since the flour was consumed raw, there was no need to build a fire that would risk revealing the soldier's location. Sesa can also be prepared from maize, though maize must be fried first, making this a less efficient preparation than for millet.

The second and most commonly mentioned dish made of millet is kotro papa (figure 9). To prepare it, a woman grinds pearl millet on a stone, adds water, and molds the mixture into balls. The balls are boiled in water, then removed and pounded lightly in the mortar. Kotro papa can be dressed with pepper, gabu (dried onion leaves), shea butter, and salt or can be eaten as is, or stew may be served alongside it. In the past, this meal was often served in the morning. There is really no similar dish made today, though one woman did describe how a government food aid called Tom Brown (a mix of bean and grain flour) was distributed in the 1980 and made into a similar dish.

The final dish is fuura (figure 10), which is much more time- and skill-intensive to produce. Some considered fuura to be chief's food, while others described it as a prepare-ahead afternoon meal. The flavor and spice combination was also unlike any of the other dishes I encountered at Banda's Olden Times Food Fair, or indeed any I had heard described in my many conversations on the topic. Fuura is made of pounded or ground millet that is mixed with water, molded into balls, and left to ferment. The balls are boiled, removed from the heat, and pounded again to give them an extra-fine texture, and spices are added. The dough is then formed again into balls which are rolled in finely ground millet flour. They may be served alone or with milk. The taste of fuura is unlike anything I had experienced in Banda or elsewhere in West Africa. It is spicy, with a distinctive clove-like bite and tangy fermented taste, and with a very fine texture.

The current status of these three dishes, as well as the many others listed in table 2, betrays one of the most common processes in food globalization: loss and the subsequent narrowing of culinary repertoires. Foodways are always changing and such losses may well be inevitable, but in chapter 6 I ask whether some of these foods may be worth saving, and what purposes they can serve.

\section{"SELL YOUR SHE GOAT" TIME OF YEAR}

The loss of pearl millet and of the knowledge needed to cultivate and cook it raises concerns about Banda's ability to cope with climate change in the future. But on the other hand, the production of pearl millet seems untenable given current environmental, economic, and cultural constraints. At the end of the day, it is unlikely that a single crop will impede people's ability to survive, because of the tremendous variety of strategies for coping with uncertain conditions. Food security is often but not always at the heart of the tensions between tradition and modernity that I have discussed in this chapter. In this section, I attempt to bring 
an experience of food insecurity to light in order to underscore its complicated relationship with modernity.

Food security was a difficult topic to discuss at first. Among my first interviews in 2009 was one with a kindly older woman in Bui, a village adjacent to the archaeological site of Bui Kataa, where we had excavated the previous summer. Archaeologists often work near modern settlements, but the inhabitants of those places are rarely part of archaeological narratives, even if their lifeways often play an uncredited role in our interpretations of the past. I was fortunate that she was among my first interviewees, for I had a tremendous amount to learn and required a patient guide.

Abena Yeli, as I will call her here, was the first to teach me not to ask directly about food security. As I learned much later, admitting to food insecurity was tantamount, for some in Banda, to admitting failure, because the inability to feed oneself was often blamed on oneself. This belief is a tell-tale sign of the embeddedness and local impacts of the mantras that inform development work, as well as of the pull-yourself/your-country-up-by-your-bootstraps nationalist discourse common in Ghana. Instead, I was to ask about the changing seasons, because that is how food was best understood. Food insecurity was something better observed than discussed, better accessed through talking about contributing factors, like rainfall or short cash reserves, rather than asking about the abstract category it has come to occupy in Western discourse. The lived experience of food insecurity is not an abstraction or a wicked sustainability challenge or any of the other ways in which it is anachronized in academic and development circles. Hunger is simply experienced, dealt with, and avoided when possible.

There are a number of well-ingrained social strategies for lessening hunger's bite. Food sharing still exists in Banda, albeit in more constrained ways than in the past, and this should be regarded as an accomplishment given that food sharing has disappeared elsewhere under similar constraints (Mandala 2005). There are strict rules about sharing with kin, especially the elderly, but depending on their income level, people also regularly share with other household members and nonkin. One of the first tactics people pursue when they run short of food or money is to borrow from kin and friends. Another common way to get by is to eat foods from the bush, as described above. People also stretch out meager food supplies by eating less. They might sell the crops that fetch higher prices at market and buy cheaper alternatives like cassava. In more extreme food shortages, people might consume cassava before they had a chance to detoxify it, or skip the starch altogether and drink only soup.

In subsequent days I returned to cook with Abena Yeli. I watched as she cooked the meat I brought as a gift and squirrelled the cooked meat away for future use. I was intrigued by the odd grey-green color of the tuo zafi she was making. At the time I thought of tuo zafi as a predictable dish of beaten grain porridge, but starting with Abena Yeli I came to realize the flexible nature of the food. Abena was 
making her food out of cassava that had been first dried and ground, as is most cassava used for $\mathrm{TZ}$ is. But hers had been dried in the wet season, when conditions were simply too wet for proper drying, so that mold encased the roots. I was visiting Abena during the height of the hungry season in late July, before corn or yams were ready to harvest, during the "sell your she-goat" (Mu sikalo pre) time of year. And cassava, she told me, is always there for you.

Only when I moved to other villages did I realize what an outlier Bui village was in terms of food preparation and food security. Part of this was the time of year-late July as the hungry season was at its worst. But the other reason was that Bui was about to be relocated in advance of flooding for the construction of the Bui hydroelectric dam. For years, government officials had told Bui villagers not to grow more than they needed, not to focus on cash crops or those which require many years to reach maturity like teak and cashew. Their fields would soon be flooded, so there was no point. The same was true of house construction. People had delayed building or repairing their own houses since they would soon be destroyed anyway.

When I visited Bui in 2009, people were willing to make these sacrifices for the good of the nation. It was their duty as Ghanaians. By 2011, when the construction of the dam was well underway but the imminent, promised move had still not happened, people were fed up. They had been living on a razor's edge of poverty and impermanence for years. Not only that, but the benefits already accruing to their neighbors, like the installation of electricity, were denied them. There were conflicting accounts about who was to blame, but people were ready to move and start their lives anew. They were the other side of modernity: the side not included. As development rolled across the Banda landscape, it was clear that its advance was patchy, unequal, and, for many, delayed (see Ferguson 1990). These hungry underbellies of modernity are often forgotten in the West's self-congratulatory stories of progress, but yet they are also modern. Adding deeper histories of remotely global places like Banda helps reveal those alternate modernities.

The advance of so-called modernity did not solve Bui's problems, and in many regards it created new ones. By the time I returned in 2014, people had been living in their new houses in the recently built Bui City for some time. I could smell fresh concrete and see the crisp lines of unchipped paint on their new, almost antiseptic, cement bunker houses. The landscape felt barren. There were no shade or fruit trees, which one finds in most villages. Those could not be moved; they had to be reestablished. But many of the town's ancestors had been moved to a burial plot not far from the houses, thanks to the involvement of archaeologists from University of Ghana. Still, even to an outsider like myself the town felt deflated. Life in the absence of a meaningful cultural landscape was quite different, as captured in Devin Tepleski's documentary Mango Driftwood (2010).

The new Bui City was something of a political experiment as well. The town was an amalgamation of Bui village and three other villages. The designation 
"city" was perhaps intended to capture this diversity, but in practice the villages operated as separately as possible. In addition to the quarters occupied by each village, another cluster of houses stood off to the side. These houses were larger, cordoned off by fences, and had their own water tanks, signaling the availability of running water inside. They were clearly better than the concrete bunkers occupied by Bui peoples. Bui villagers were bitter. These houses were not for Africans at all, but for foreigners coming to work on the dam. Tensions between the diverse occupants at Bui were high, and did not show any prospect of abating.

Development is not a panacea. Often, it exacerbates old inequalities-between chiefs and constituents, haves and have nots, women and men-and can also act to create new disparities (Carr 2008; Cliggett 2005). As Bui's example illustrates, food in particular is often strongly impacted by development schemes and modernization. From the long-term perspective offered in this book, we can see that developments like the Bui dam are sedimented on top of earlier shifts like market integration, building on their imperfections, deepening the crevasses of inequality. We must understand those histories in order to work towards a better future, a subject I continue in the final chapter.

\section{HUNGRY UNDERBELLIES OF MODERNITY}

In this chapter, I have covered only a small number of the many tensions that inhabit remotely global foodways in Banda. I have tried to coax to the surface the decisions people make on a daily basis in order to feed their families in a manner that subverts the scarcities they face. This subversion is two-fold, as it involves satisfying nutritional needs despite declining food availability, while also lessening scarcity's bite by preparing and consuming desired and culturally valued foods. Navigating this tension means negotiating between the two definitions of scarcity discussed in chapters 1 and 2, of measurable, quantifiable need and the perception of need. As it turns out, eating while remotely global involves balancing both.

In some cases, people have avoided both scarcities by adhering to tried-and-true traditions, like wild leaf soup and tuo zafi. This adherence may at times be a conscious choice, at others an unintentional one grounded in bodily reproduction, and at still others a function of less choice brought on by poverty. Likewise the appropriation of foreign foods and things falls on a similar spectrum of choice and lack of choice, especially in this remotely global place where funds do not always permit access to the most desirable foods, like rice or fresh meat. Yet people continue to choose what is best for them based on their circumstances at the time; such appropriations are not disempowering capitulations to outside pressures, but active strategies that build rapidly evolving local tastes.

Balancing real scarcities by avoiding the perception of hardship is a dialectic, always in flux, and appreciating that constant movement means we cannot regard African food practices as timeless and unchanging no matter how traditional they 
may appear in the eyes of outsiders. As Piot (1999) has argued, life in an African village is just as modern as in London. Africans have been enmeshed in the very same global systems as British city dwellers for centuries, but the power dynamics have been unequal for a very long time. Out of these inequalities two modernities were born: the well-fed and the hungry underbelly. In these hungry underbellies of modernity, people regularly deal with seasonal food insecurity. But at the same time, they hunger to be part of the other modernity, the well-fed one. Aspiring to eat like urbanites, with their ready access to mass-produced convenience foods, helps the youth in Banda feel like they are part of the modern world. In the concluding chapter, I consider how these modernities might be reconciled. 